Revista Brasileira de Agricultura Irrigada v.13, nº.6, p. 3783 - 3791, 2019

ISSN 1982-7679 (On-line)

Fortaleza, CE, INOVAGRI - http://www.inovagri.org.br

DOI: $10.7127 /$ rbai.v13n6001165

Protocolo 1165.19 - 00/05/2020 Aprovado em 09/05/2020

\title{
TOLERÂNCIA DE HÍBRIDOS DE PEPINO À NÍVEIS DE SALINIDADE EM AMBIENTE PROTEGIDO
}

\author{
Kevim Muniz Ventura ${ }^{1}$, Dávilla Alessandra Da Silva Alves², Hélio Grassi Filho³, Rodrigo Máximo \\ Sánchez Román ${ }^{4}$
}

\section{RESUMO}

Os efeitos da salinidade sobre o desenvolvimento e rendimento das culturas vêm ganhando atenção, no que diz respeito a habilidade das cultivares em reagir aos efeitos salinos decorrentes do uso de águas de baixa qualidade. Neste sentido, o objetivo deste trabalho foi avaliar o comportamento de dois híbridos de pepino (Aodai Melhorado e Caipira), submetidos a quatro níveis de salinidade (0,7;

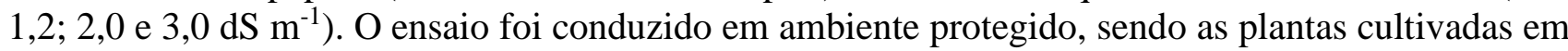
recipientes com volume útil de 20 litros de solo. Foi adotado o delineamento em blocos inteiramente casualizado. O monitoramento da condutividade elétrica foi realizado por meio de extratores de solução, com auxílio de condutivímetro portátil. Com base nos resultados e nas analises estatísticas, o híbrido Aodai Melhorado apresentou uma maior tolerância a salinidade, mantendo os mesmos valores entre os parâmetros analisados para as diferentes doses de salinidade aplicadas.

Palavras-chave: Irrigação, estresse salino, Cucumis sativus L.

\section{TOLERANCE OF CUCUMBER HYBRIDS WITH DIFFERENT LEVELS OF SALINITY UNDER PROTECTED ENVIRONMENT}

\begin{abstract}
The effects of salinity on crop yield have been gaining attention as regards the ability of cultivars to react to saline effects from the use of low-quality water. The objective of this work was to evaluate the behavior of two cucumber hybrids (Aodai Melhorado and Caipira), submitted to four salinity levels $\left(0.7,1.2,2.0\right.$ and $\left.3.0 \mathrm{dS} \mathrm{m}^{-1}\right)$. The experiment was conducted in a protected environment, with the plants cultivated in containers with a useful volume of 15 liters of soil. A completely randomized block design was adopted. The electrical conductivity monitoring was carried out using solution

\footnotetext{
${ }^{1}$ Doutorando em Agronomia (Irrigação e Drenagem), Departamento de Engenharia rural, FCA/UNESP Botucatu/SP, Brasil.kkkevim@hotmail.com

${ }^{2}$ Doutoranda em Agronomia (Irrigação e Drenagem), Departamento de Engenharia rural, FCA/UNESP Botucatu/SP, Brasil.davilla.alessandra@gmail.com

${ }^{3}$ Professor do Departamento de Solos, FCA/UNESP Botucatu/SP, Brasil. helio.grassi@ @unesp.br

${ }^{4}$ Professor do Departamento de Engenharia Rural, FCA/UNESP Botucatu/SP, Brasil. rodrigo.roman@unesp.br
} 
extractors, using a portable conductivity meter. Based on the results and statistical analyzes, the Aodai Melhorado hybrid presented a higher tolerance to salinity, maintaining the same values among the parameters analyzed for the different salinity rates applied.

Keywords: Irrigation, saline stress, Cucumis sativus $L$.

\section{INTRODUÇÃO}

Pertencente à família Cucurbitaceae, o pepino (Cucumis sativus L.) é uma espécie de clima quente, e possui boa adaptação a temperaturas amenas, especialmente quando cultivado em ambiente protegido. Contudo, o cultivo em casas de vegetação apresenta riscos, especialmente devido redução da qualidade da irrigação por ocasião do uso recorrente de fertilizantes, resultando em níveis elevados de salinidade do solo ou do substrato (VIEIRA NETO; JÚNIOR; GONÇALVES, 2020).

De acordo com Medeiros et al. (2010) o pepino é uma das principais hortaliças cultivadas em ambiente protegido. Apresenta grande importância no comercio brasileiro devido a sua grande aceitação como principal componente de saladas (MARTINS; LUZ; ENCK, 2018). Entre os principais cultivados estão os grupos Aodai, Caipira e Japonês, sendo que a região Sudeste e Nordeste apresentam as maiores produtividades, oscilando entre 40 a 50 t/ha (FILGUEIRA, 2008; AGRIANUAL, 2010).

De acordo com Fontes (2005) inúmeros fatores estão ligados a produtividade da cultura de pepino, sendo eles: estande, temperatura, sanidade, duração do ciclo, nutrição e irrigação. A irrigação é uma alternativa que gera aumentos consideráveis na produtividade de culturas quando bem dimensionada e manejada (PRADO e COLOMBO, 2007), a pratica é considerada uma forma de garantir a necessidade hídrica da cultura de forma que a mesma possa expressar todo seu potencial gerando altas produtividades, e muitas vezes tornando uma área mais eficiente economicamente em áreas que a produção não seria possível (HERNANDEZ, 2004; KING et al., 2020; FADUL et al., 2020). Quando se trata de cultivo em ambiente protegido, a irrigação é essencial, e aliado ao adequado manejo de fertilizante, possibilita a obtenção de elevadas produtividades. Porém quando realizada de forma inadequada pode causar resultados desastrosos, como a salinização do solo.

Por isso, um fato importante que deve ser considerado durante o manejo de culturas irrigadas é a tolerância das culturas à salinidade, que é definido como a capacidade da cultura a suportar certos níveis de sais (OLIVEIRA et al., 2015). O pepino apresenta sensibilidade moderada à salinidade, entretanto, os valores máximos são comumente ultrapassados devido aos níveis de salinidade encontrados na água de irrigação, o que pode gerar prejuízos para a cultura (MEDEIROS et al., 2010; SANTANA, CARVALHO e MIGUEL, 2010).

Dessa forma, visando produzir dados científicos que permitam o cultivo de dois híbridos de pepino em condições não ideais, teve-se como objetivo nesse trabalho avaliar o comportamento produtivo da cultura em resposta a quatro níveis de salinidade $(0,7 ; 1,2$; 2,0 e $2,5 \mathrm{dS} \mathrm{m}^{-1}$ ).

\section{MATERIAL E MÉTODOS}

O ensaio foi instalado em ambiente protegido localizado no Departamento de Solos e Recursos Ambientais da Faculdade de Ciências Agronômicas/ Botucatu - SP nas coordenadas $22^{\circ} 52^{\prime} 55^{\prime}$ ' S e $48^{\circ} 26^{\prime} 22^{\prime \prime}$ ' W a $786 \mathrm{~m}$ de altitude, de março a julho de 2017. O clima da região é Cwa, consiante a classificação proposta por Koppen, como tropical de altitude, verão quente úmido e estiagem no inverno.

Para a condução do experimento, foram utilizados recipientes de Policloreto de vinil (PVC-plástico) com volume útil para 20 litros de solo, classificado Latossolo Vermelho distrófico (Figura 1A). As mudas foram 


\section{TOLERÂNCIA DE HÍBRIDOS DE PEPINO À NÍVEIS DE SALINIDADE EM AMBIENTE PROTEGIDO}

transplantadas 25 depois da semeadura em bandejas de poliestireno expandido com 128 células.

Foi utilizado um Latossolo Vermelho distrófico segundo a classificação da EMBRAPA (2013), com as seguintes características físico-químicas: $\mathrm{pH}-4.1$; M.O - 13,0 g dm-3; Presina - 3,0 mg dm-3; Al - 13 mmolc dm-3; H+Al - 65 mmolc dm-3; SB 3,3 mmolc dm-3; CTC - 68 mmolc dm-3; K 0,3 mmolc dm-3; $\mathrm{Ca}-2,0$ mmolc dm-3; $\mathrm{Mg}-$
1,0 mmolc dm-3 e V\% - 5,0. As adubações e correção antes do ensaio foram realizadas de acordo com as recomendações propostas por Raij et al. (1997), para a cultura do pepino.

$\mathrm{O}$ delineamento experimental adotado foi inteiramente casualizado com cinco repetições. As plantas foram tutoradas com o auxílio de fitilho (Figura 1B), conforme determinado em Dumont, Dias e Finger (2016) como uma das técnicas mais utilizadas por produtores de pepino.

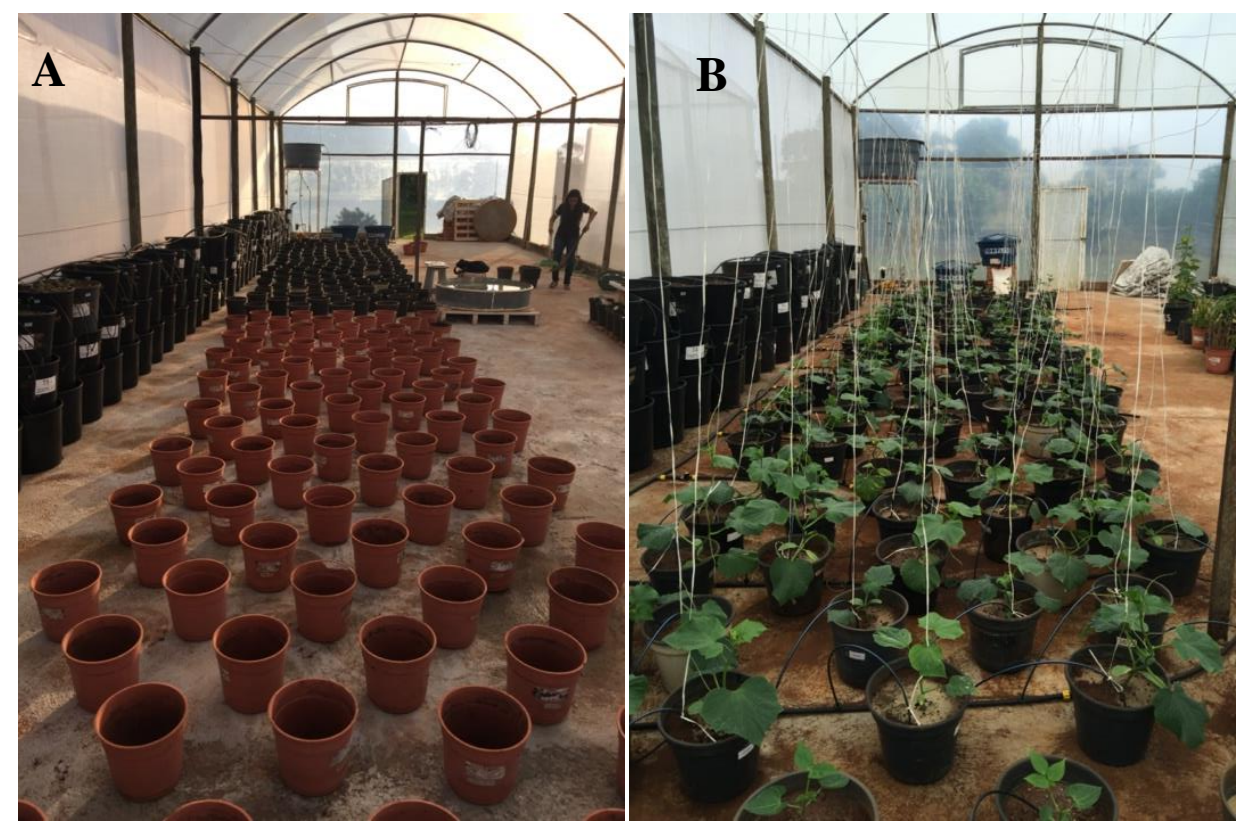

Figura 1. A: Vasos distribuídos para o plantio da cultura na estufa. B: Sistema de tutoramento com fitilho.

Foi avaliado o comportamento de dois híbridos de pepino, híbrido 1: Aodai Melhorado e híbrido 2: Caipira, submetido a quatro níveis de salinidade $(0,7 ; 1,2 ; 2,0$ e 2,5 $\mathrm{dS} \mathrm{m}^{-1}$ ). Para alcançar os níveis de salinidades foi utilizado a metodologia proposta por Lima et al. (2001), onde se diluí $\mathrm{NaCl}$, obtendo os valores de condutividade elétrica (CE) desejados. $\mathrm{O}$ monitoramento da $\mathrm{CE}$ foi realizado por meio de extratores de solução, com auxílio de condutivímetro portátil diariamente, após a irrigação.
As lâminas diárias de irrigação foram aplicadas por gotejamento superficial (Figura 2), com emissores tipo PCJ com vazão nominal de $4 \mathrm{~L} \mathrm{~h}^{-1}$, determinadas pelo método do Tanque Classe A para determinação da evaporação e através de um coeficiente Kp estimar a evapotranspiração, e corrigida pelo coeficiente da cultura do pepino ( $\left.\mathrm{Kc}_{\text {pepino}}\right)$ ajustado ao estágio de desenvolvimento da planta, de acordo com Bernardo et al. (2008), considerando $95 \%$ de eficiência do sistema. 


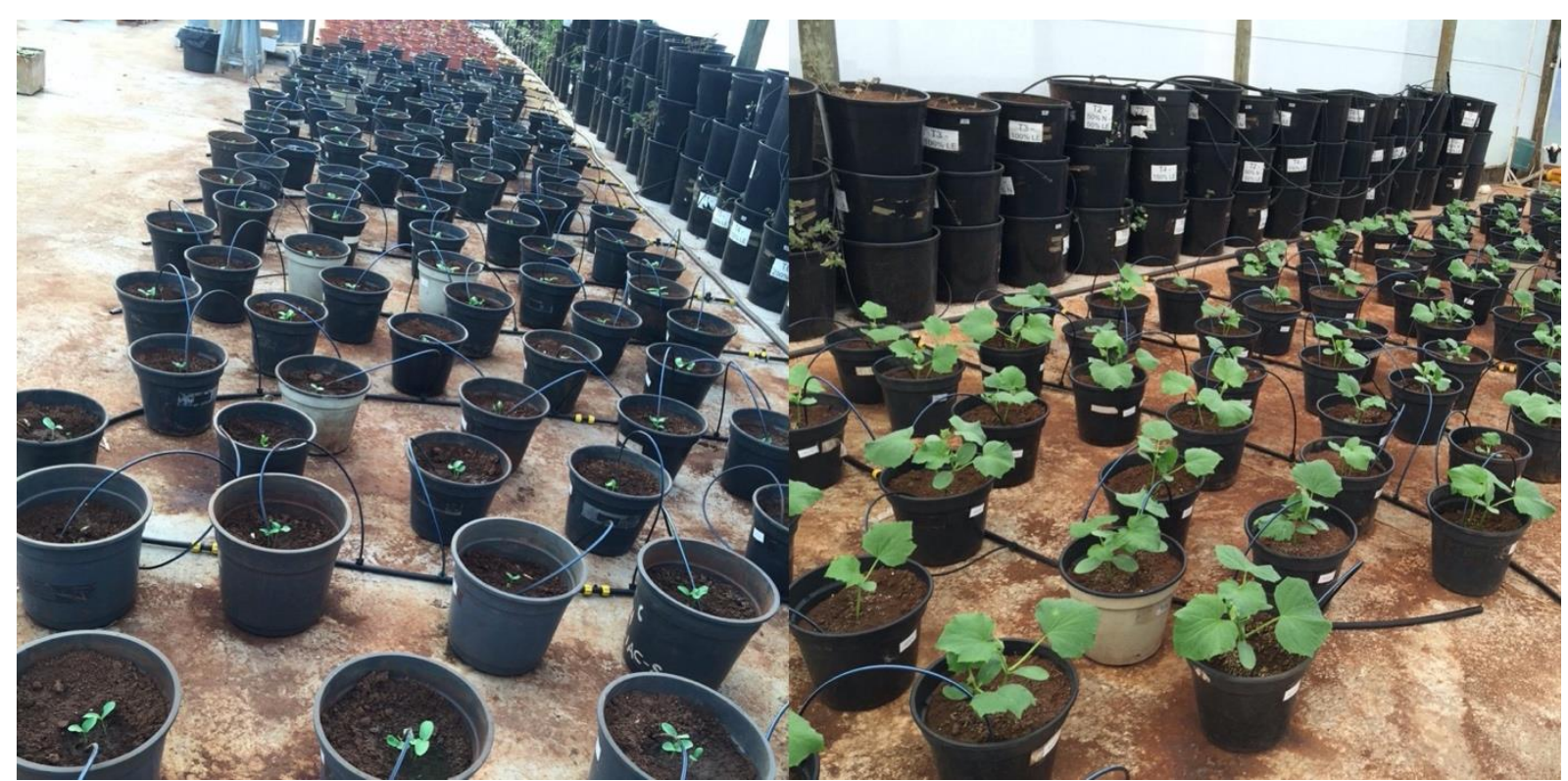

Figura 2. Vasos com sistema de irrigação localizada por gotejamento.

Para a obtenção dos resultados, foram avaliadas altura da planta e massa fresca e seca da parte aérea, diâmetro do fruto $(\mathrm{cm})$, peso do fruto $(\mathrm{cm})$ e comprimento do fruto (cm) e teor de sólidos solúveis ( ${ }^{\circ}$ Brix). Os parâmetros medidos em centímetros foram avaliados com o auxílio de uma régua e uma trena, os medidos em gramas com uma balança, e os sólidos solúveis com auxílio de um refratômetro óptico portátil modelo $\mathrm{RCZ}$ da marca Bel engineering (Faixa de leitura 0 a $32 \%)$.

As análises estatísticas dos resultados foram realizadas no software RStudio Versão 1.2.1335 e submetidas à análise de variância, com as médias comparadas pelo teste de Tukey à $5 \%$ de significância. Posteriormente, os resultados foram submetidos à análise de regressão.

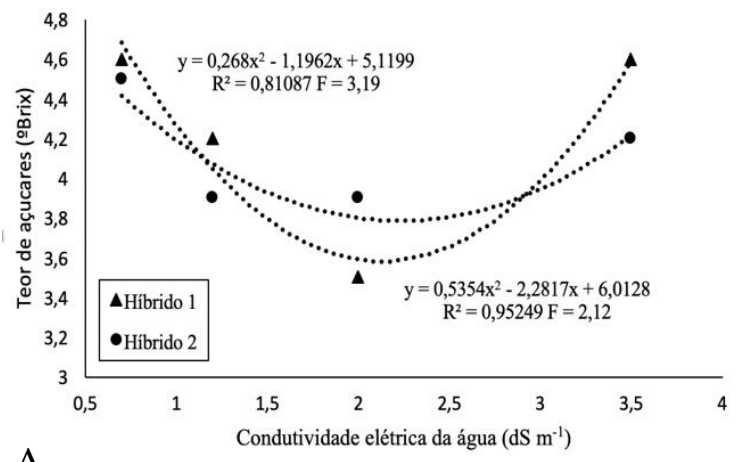

A

\section{RESULTADOS E DISCUSSÃO}

$\mathrm{Na}$ figura 3 estão dispostas as análises de regressão das médias para as variáveis analisadas referente ao fruto: peso fresco, teor de açucares, comprimento e diâmetro correlacionando-as com os diferentes níveis de salinidade da água, representados pela condutividade elétrica (CE) da mesma.

Para as variáveis relacionadas as dimensões do fruto, observa-se que no híbrido 1 houve uma superioridade nos níveis intermediários, já para o híbrido 2 houve uma queda nos valores médios de CE para peso fresco e comprimento, comportamento contrário para a variável diâmetro. Já para o parâmetro químico, teor de açúcares, ambos os híbridos apresentaram uma redução nos teores de açúcares nos níveis intermediários de salinidade.

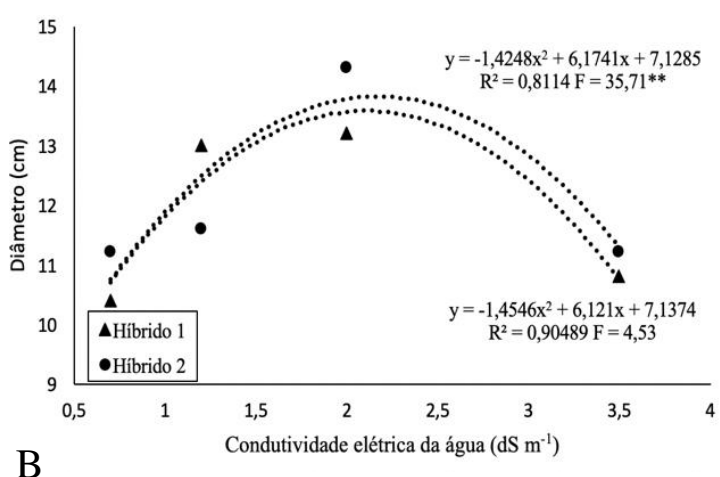

B 

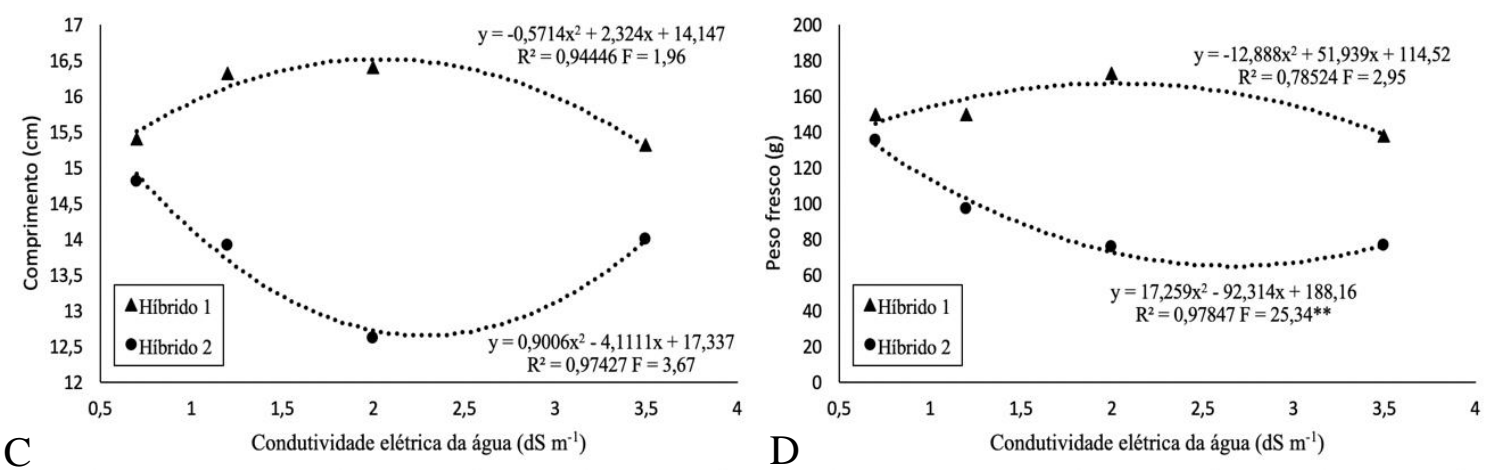

Figura 3. Análises de regressão para as variáveis teor de açúcares (A), diâmetro (B), comprimento do fruto (C) e peso fresco (D) em função da salinidade da água de irrigação.

Para ambos os híbridos, nos parâmetros comprimento do fruto e teor de açúcares não houve diferença estatística, porém no híbrido 2 houve uma redução nos níveis intermediários de salinidade. Segundo Santana, Carvalho e Miguel (2010) o aumento da salinidade resulta em um maior nível de sais depositados no solo, o que altera o potencial osmótico e reduz o consumo de água pelas plantas, assim como nutrientes que serão usados na produção das reservas de açúcares do fruto, nos resultados é possível observar que até o tratamento intermediário $\left(2,0 \mathrm{dS} \mathrm{m}^{-1}\right)$ houve uma queda no teor de açucares, evidenciando o estresse causado na planta pela salinidade.

Entretanto, no tratamento de maior CE $\left(3,5 \mathrm{dS} \mathrm{m}^{-1}\right)$ ocorreu um incremento no teor de açucares, isso pode ser explicado pois o aumento de açucares solúveis faz parte da estratégia das plantas para lidar com o estresse osmótico resultante da salinidade. Os osmóticos orgânicos servem de proteção para as estruturas celulares através da interação com as membranas e enzimas, e segundo Esteves e Suzuki (2008) os açucares representam cerca de $50 \%$ destes compostos. A determinação dos teores de açucares no fruto vem sido relatado como um bom indicador da adaptação vegetal às condições salinas do solo e da água (ZHANG et al., 2012; RADIĆ et al. 2013; LI et al. 2017).

Já para peso fresco e diâmetro do fruto, nota-se que os frutos do híbrido 2 sofreram mais variação conforme a dose de salinidade aplicada, apresentando melhor resultado para o tratamento controle (salinidade igual a 0,7 $\mathrm{dS} \mathrm{m}^{-1}$ ), enquanto o híbrido 1 não apresentou diferenças estatística entre os tratamentos, mostrando assim sua maior resistência a salinidade.

Os resultados mostram que o híbrido 1 apresentou frutos mais pesados no tratamento com CE de 2,0 dS m $\mathrm{d}^{-1}$, enquanto o híbrido 2 expressou melhores resultados no tratamento controle, com CE de 0,7 dS $\mathrm{m}^{-1}$. Blanco (1999) aponta que por se tratar de uma cultura com sensibilidade moderada à salinidade, o pepino pode apresentar híbridos e cultivares com maior ou menor tolerância a sais. $\mathrm{O}$ autor cita ainda que os principais efeitos da salinidade na cultura são redução no número de frutos, altura de plantas e matéria seca, porém mesmo com esses efeitos o fruto em si não apresenta tanta sensibilidade, podem alcançar níveis satisfatórios de produção mesmo com a planta sofrendo com o estresse salino.

Em relação a planta, na figura 4 estão dispostas as análises de regressão das médias para as variáveis: número de folhas, altura, peso fresco e seco da parte aérea relacionando-as com os diferentes níveis de salinidade da água. Ambos os híbridos apresentaram comportamento semelhantes nas quatro variáveis analisadas. Para altura, peso fresco e seco da parte aérea, houve queda nos valores encontrados, enquanto número de folhas apresentou os melhores resultados nos níveis intermediários de salinidade. 

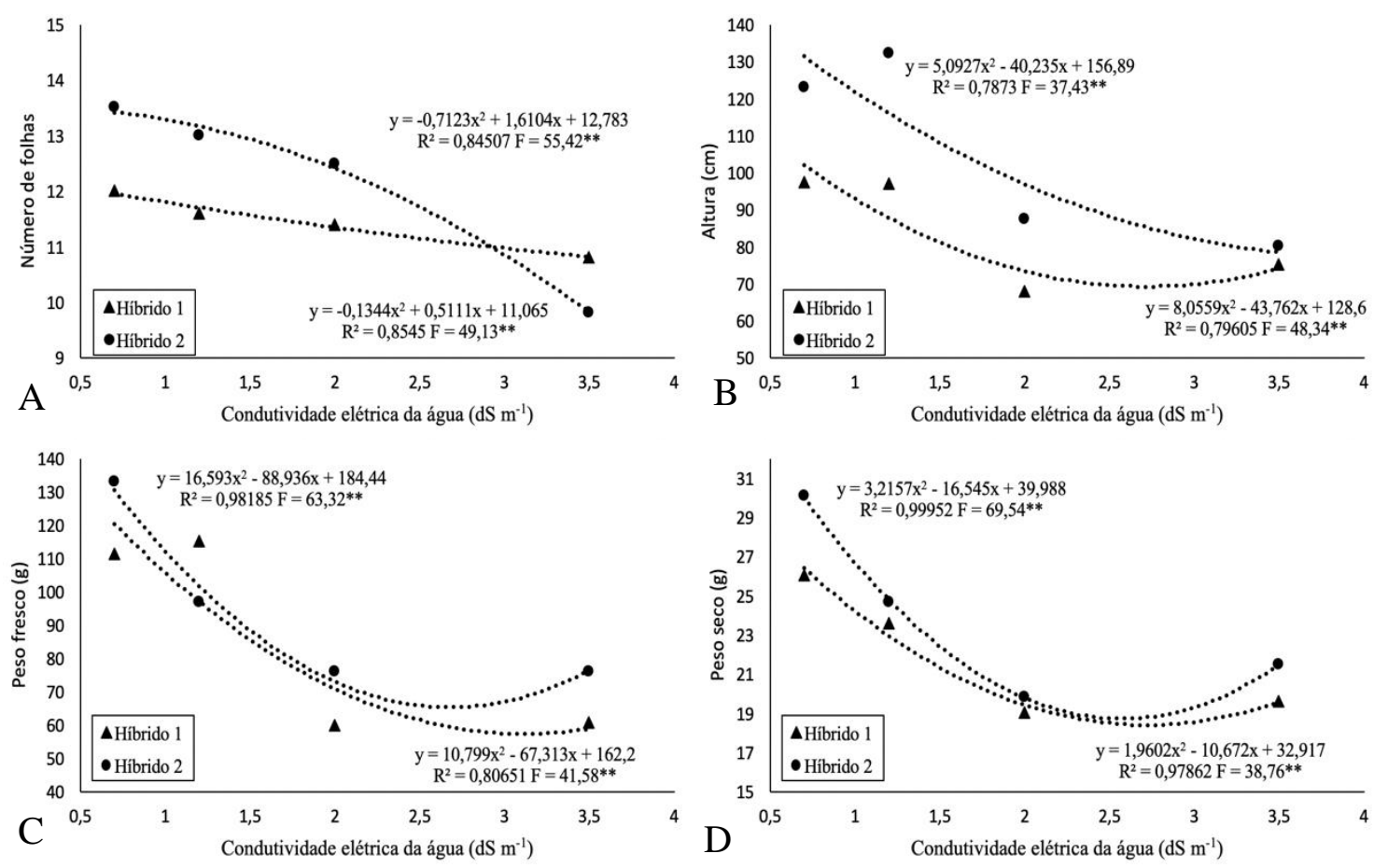

Figura 4. Análises de regressão para as variáveis número de folhas (A), altura da planta (B), peso fresco (C) e seco (D) da planta em função da salinidade da água de irrigação.

Na Figura 4, é possível observar os resultados para os parâmetros analisados na planta nos tratamentos utilizados no experimento. Para esses parâmetros, ambos os híbridos apresentaram diferenças estatísticas entre os tratamentos, evidenciando que a planta sofre interferência devido ao aumento da salinidade e corroborando com a afirmação dede acordo com Medeiros, Duarte e Dias et al. (2009) e Bezerra et al. (2016), de que dentre os efeitos prejudiciais dos sais nas plantas está a redução e desuniformidade no crescimento vegetativo. Os resultados mostram que para número de folhas e altura, os melhores resultados foram o do tratamento controle (salinidade igual a $0,7 \mathrm{dS} \mathrm{m}^{-1}$ ) e o pior o do tratamento de maior salinidade $(3,5$ $\mathrm{dS} \mathrm{m}^{-1}$ ). De acordo com Graciano et al. (2011), as respostas fisiológicas das culturas agrícolas submetidas a estresse salino são variadas, destacando-se as modificações no crescimento. Segundo Nascimento et al. (2015), os resultados para número de folhas e altura da planta pode ser explicado devido ao aumento da condutividade elétrica que resulta em distúrbios nas membranas e alterações na condutância estomática e fotossíntese, e consequentemente reduzindo a produção de biomassa pelas plantas. Resultados semelhantes foram encontrados por Eloi et al. (2007) e Oliveira et al. (2007) em plantas irrigadas com águas com elevada CE.

Santana, Carvalho e Miguel et al. (2010), em um experimento com salinidade utilizando o híbrido Caipira também identificaram sua sensibilidade à salinidade. Os autores ainda apontam que a maior produtividade encontrada foi a do tratamento controle (água de abastecimento). Alburqueque et al. (2016) aponta que o híbrido Aodai Melhorado apresenta uma certa diminuição de massa seca com o aumento da salinidade, fato que também foi observado neste trabalho (Figura 4).

Para os parâmetros peso fresco e seco, ambos os híbridos apresentaram o mesmo comportamento, maiores valores encontrados no tratamento controle e uma diminuição continua como aumento da CE. O mesmo padrão foi encontrado por Lima et al. (2015) que afirmou que um dos efeitos da salinidade nas plantas é a diminuição do alongamento celular que pode causar a diminuição do peso fresco.

Os resultados apresentados nas figuras acimas corroboram o dito por Blanco (1999) 
em que as plantas sofreram com o aumento da salinidade, porém os parâmetros dos frutos não foram tão afetados. Também se observa que apesar das plantas em ambos os híbridos apresentarem valores inferiores para as maiores salinidades, os frutos do híbrido 1 mantiveram valores ideais de produção. $\mathrm{O}$ estresse salino é um dos fatores abióticos que mais limita o desenvolvimento e produtividade de culturas agrícolas, desta forma, a tolerância das culturas definida como a capacidade das plantas de suportar certos níveis de sais na água ou no solo, sem prejudicar significativamente sua produção ou qualidade, quando se comparar os dados com condições ideais de cultivo, é uma característica de grande importância no meio agrícola (MAAS, 1990; FREIRE et al., 2014).

Considerando os dados obtidos no experimento, principalmente os descritos na Figura 3 que diz respeito aos frutos, o híbrido 1 se mostrou mais tolerante, uma vez que a ele manteve valores adequados com o aumento da salinidade. $\mathrm{O}$ híbrido 2 apresentou uma sensibilidade elevada à salinidade, em concordância com Santana, Carvalho e Miguel (2010), que trabalhando com o mesmo híbrido Caipira encontrou resultados semelhantes em experimento em condição de campo.

\section{CONCLUSÕES}

O híbrido 1, Aodai Melhorado, apresentou uma maior tolerância aos níveis de salinidades, uma vez que os parâmetros analisados do fruto e da planta se mantiveram estáveis com o aumento da condutividade elétrica da água.

O híbrido 2, Caipira, apresentou parâmetros determinantes de produtividades inferiores com o aumento da condutividade elétrica da água de irrigação, mostrando assim sua sensibilidade à salinidade.

\section{REFERÊNCIAS BIBLIOGRÁFICAS}

ALBUQUERQUE, J. R. T.; SÁ, F. V.; OLIVEIRA, F. A.; ARAUJO, E. B. G.;
SOUTO, L. S.. Crescimento inicial e tolerância de cultivares de pepino sob estresse salino. Revista Brasileira de Agricultura Irrigada, [s.1.], v. 10, n. 2, p.486-495, 29 abr. 2016.

INOVAGRI. http://dx.doi.org/10.7127/rbai.v10n200355.

BEZERRA, Jeferson Dutra; PEREIRA, Walter Esfrain; SILVA, José Madson da; RAPOSO, Roberto Wagner Cavalcanti. Crescimento de dois genótipos de maracujazeiro-amarelo sob condições de Salinidade. Revista Ceres, [s.1.], v. 63, n. 4, p. 502-508, ago. 2016. FapUNIFESP (SciELO). http://dx.doi.org/10.1590/0034$737 \times 201663040010$.

BLANCO, F. F.. Tolerância do pepino enxertado à salinidade em ambiente protegido e controle da salinização do solo. 2009. 122 f. Dissertação (Mestrado) Curso de Agronomia, Esalq, Piracicaba, 2009.

DUMONT, ARMANDO HORTA; DIAS, LUIZ ANTONIO DOS SANTOS; FINGER, FERNANDO L. Oferta e tecnologias de produção de pepino e berinjela em Minas Gerais. Horticultura Brasileira, [s.1.], v. 34, n. 2, p. 412-422, jan. 2016.

ELOI, M. W.; DUARTE, N. S.; SOARES, M. T. Níveis de salinidade e manejo da fertirrigação sobre características do tomateiro cultivado em ambiente protegido. Revista Brasileira Ciências Agrárias. v. 2, n. 1. p. 83-89, 2007.

ESTEVES, Bruno dos Santos; SUZUKI, Marina Satika. Efeito da salinidade sobre as plantas. Oecologia Brasiliensis, [s.1.], v. 12, n. 4, p. 662-680, dez. 2008.

FADUL, E.; MASIH, I.; FRAITURE, F.x.. Irrigation performance under alternative field designs in a spate irrigation system with large field dimensions. Agricultural Water 
Management, [s.1.], v. 231, p. 105989105999, mar. 2020. Elsevier BV. http://dx.doi.org/10.1016/j.agwat.2019.105989

FILGUEIRA, F. A. R.. Novo manual de olericultura: agrotecnologia moderna na produção e comercialização de hortaliças. 2 . ed. Viçosa: Embrapa, 2008.

FREIRE, José Lucínio de Oliveira; DIAS, Thiago Jardelino; CAVALCANTE, Lourival Ferreira; FERNANDES, Pedro Dantas; LIMA NETO, Antonio João de. Rendimento quântico e trocas gasosas em maracujazeiro amarelo sob salinidade hídrica, biofertilização e cobertura morta. Revista Ciência Agronômica, [s.1.], v. 45, n. 1, p. 82-91, mar. 2014. FapUNIFESP (SciELO). http://dx.doi.org/10.1590/s1806-

66902014000100011.

FNP, Instituto. Agrianual 2010: anuário da agricultura brasileira. São Paulo: Fpn, 2010.

GRACIANO, Erika S. A.; NOGUEIRA, Rejane J. M. C.; LIMA, Danúbia R. M.; PACHECO, Cinthya M.; SANTOS, Roseane C.. Crescimento e capacidade fotossintética da cultivar de amendoim BR 1 sob condições de salinidade. Revista Brasileira de Engenharia Agrícola e Ambiental, [s.1.], v. 15, n. 8, p. 794-800, ago. 2011. FapUNIFESP (SciELO). http://dx.doi.org/10.1590/s141543662011000800005.

HERNANDEZ, F. B. T. Manejo da irrigação. 2004. Disponível em <http://www.irrigaterra.com.br/manejo.php>. Acesso em 27 abril. 2020.

KING B.A., STARK J.C., NEIBLING H. (2020) Potato Irrigation Management. In: Stark J., Thornton M., Nolte P. (eds) Potato Production Systems. Springer, Cham LI, Q.; YANG, A.; ZHANG, W.H. Comparative studies on tolerance of rice genotypes differing in their tolerance to moderate salt stress. BMC Plant Biol, v.17, p.141, 2017.
LIMA, K. L.; CAVALCANTE, L. F.; FEITOSA FILHO, J. C. Efeito de fontes e níveis de salinidade da água de irrigação sobre a germinação e o crescimento da pinheira. Engenharia Agrícola, Jaboticabal, v. 21, n. 2, p. 135-144, 2001.

LIMA, Luan Alves; OLIVEIRA, Francisco de Assis de; ALVES, Rita de Cássia; LINHARES, Paulo Sérgio Fernandes; MEDEIROS, Arthur Manoel Alves de; BEZERRA, Francisco Mardones Servulo. Tolerância da berinjela à salinidade da água de irrigação. Revista Agroambiente On-line, [s.1.], v. 9, n. 1, p. 27-34, 1 mar. 2015. Zeppelini Editorial e Comunicacao. http://dx.doi.org/10.5327/z1982-

8470201500012202

MAAS, E. V. Crop salt tolerance. In: Tanji, K. K. (ed.) Agricultural salinity assessment and management manual. New York: ASCE, 1990. chap. 13, p. 262-304.

MARTINS, J. K. D.; LUZ, S. R. O. T.; ENCK, B. F.. Avaliação da produtividade do pepino conduzido em sistemas de tutoramento horizontal e vertical com e sem consórcio com amendoim em rondônia. Enciclopédia Biosfera, Goiânia, v. 15, n. 27, p.152-162, jun. 2018.

MEDEIROS, PEDRO R. F. DE; DUARTE, SÉRGIO N.; DIAS, CARLOS T. S.. Tolerância da cultura do pepino à salinidade em ambiente protegido. Revista Brasileira de Engenharia Agrícola e Ambiental, v. 13, n. 4, p. 406-410, jan. 2009.

MEDEIROS, P. R. F.; DUARTE, S. N.; DIAS, C. T. S.; SILVA, M. F. D.. Tolerância do pepino à salinidade em ambiente protegido: efeitos sobre propriedades físico-químicas dos frutos. Irriga, v. 15, n. 3, p.301-311, jun. 2010.

NASCIMENTO, Iarajane Bezerra do; MEDEIROS, José Francismar de; ALVES, Samara Sibelle Vieira; LIMA, Breno Leonan de Carvalho; SILVA, José Leôncio de 
Almeida. Desenvolvimento inicial da cultura água de irrigação em dois tipos de solos. Agropecuária Científica no Semiárido, v. 11, n. 1, p. 37-43, abr. 2015.

OLIVEIRA, F. A.; SÁ, F. V. S.; PAIVA, E. P.; ARAÚJO, E. B. G.; SOUTO, L. S.; ANDRADE, R. A.; SILVA, M. K. N. Emergência e crescimento inicial de plântulas de beterraba cv. Chata do Egito sob estresse salino. Agropecuária Científica no Semiárido, v. 11, n. 1, p. 01-06, 2015.

OLIVEIRA, F. A.; MEDEIROS, J. F. de; OLIVEIRA, M. K. T.; LIMA, C. J. G. de; GALVÃO, D. de C. Desenvolvimento inicial do milho-pipoca 'Jade' irrigado com água de diferentes níveis de salinidade. Revista Verde de Agroecologia e Agricultura Sustentável, v. 2, n. 1, p. 45-52, 2007.

PRADO, G.; COLOMBO, A. Análise da uniformidade de aplicação de água pelo aspersor plona-rl250 em sistemas autopropelidos de irrigação. Irriga, v. 12, n. 2, p.249-262, abr. 2007.

R CORE TEAM (2019). R: A language and environment for statistical computing. $R$ Foundation for Statistical Computing, Vienna, Austria. URL: https://www.Rproject.org/. Acesso em 27 abril. 2020.

RADIC, S; STEFANIC, P.P.; LEPEDUS, H.; ROJE, V.; PEVALEK-KOZLINA, B. Salt do pimentão influenciado pela salinidade da tolerance of Centaurea ragusina $\mathrm{L}$. is associated with efficient osmotic adjustment and increased antioxidative capacity. Environ Exp Bot, v. 87, p.39-48, 2013.

RAIJ, B. Van et al. Recomendações de adubação e calagem para o estado de São Paulo. 2.ed. Campinas: instituto agronômico/ fundação IAC. 1997. 285p.

SANTANA, MÁRCIO JOSÉ DE; CARVALHO, JACINTO DE ASSUNÇÃO; MIGUEL, DOUGLAS DA SILVA. Respostas de plantas de pepino à salinidade da água de irrigação. Global Science And Technology, [s. L.], p. 94-102, dez. 2010.

VIEIRA NETO, João; MENEZES JÚNIOR, Francisco Olmar Gervini de; GONÇALVES, Paulo Antônio de Souza. Avaliação da produção de cultivares de pepino para conserva e de mini tomate com e sem aplicação de fertilizante foliar. Revista Thema, [s.1.], v. 16, n. 4, p. 855-865, 14 jan. 2020. Instituto Federal de Educacao, Ciencia e Tecnologia Sul-Rio-Grandense. http://dx.doi.org/10.15536/thema.v16.2019.85 5-864.1473.

ZHANG, H; HAN, B; WANG, T; CHEN, S.X.; LI, H. Y. Mechanisms of plant salt response: insights from proteomics. J Proteome Res, v.11, p.49-67, 2012. 